\title{
OS DISPOSITIVOS MÓVEIS NO PROCESSAMENTO DE ROBÔS DE BAIXO CUSTO
}

\author{
A. G. da Silva Júnior', R. V. Aroca², A. M. F. Burlamaqui', L. M. G. Gonçalves²
}

${ }^{1}$ Escola de Ciências e Tecnologia - Universidade Federal do Rio Grande do Norte

${ }^{2}$ Lab. NatalNet - Depto de Eng. da Computação e Automação - Universidade Federal do Rio Grande do Norte

Artigo submetido em outubro/2011 e aceito em novembro/2011

\section{RESUMO}

Tendo em vista a evolução da robótica, aquilo que ela representa no cenário mundial e as dificuldades enfrentadas pelo Brasil para seguir o desenvolvimento dessa área de pesquisa, principalmente com relação aos preços inacessíveis de kits de robótica à realidade brasileira, torna-se interessante desenvolver robôs de baixo custo. E ainda, levando em consideração o avanço dos dispositivos móveis em um contexto mundial, desenvolveu-se um sistema robótico de baixo custo que pode ser programado e controlado por qualquer dispositivo móvel que emita sons, utilizando seus componentes e seu processamento para uma determinada operação.

PALAVRAS-CHAVE: Robótica, baixo-custo, dispositivos móveis, celular.

\section{THE USE OF MOBILE DEVICES AS PROCESSING UNITS OF LOW COST ROBOTS}

\section{ABSTRACT}

Given the evolution of robotics, what it represents in the world's scenario and the Brazilian difficulties to follow the development of this research area, specially regarding the inaccessible costs of robotics kits, it becomes interesting to develop low cost robots. Moreover, considering the advances of mobile devices in a world wide context, a low cost robotic system that can be controlled and programmed by any mobile device that can produce sounds was developed. The accessories of the mobile device can also be used to aid the execution of some operation done by the robot.

KEY-WORDS: Robotics, low-cost, mobile devices, cell phone. 


\section{OS DISPOSITIVOS MÓVEIS NO PROCESSAMENTO DE ROBÔS DE BAIXO CUSTO}

\section{INTRODUÇÃO}

Apesar de ser uma área em franca expansão no mundo e uma das áreas mais representativas das novas tecnologias, a robótica no Brasil tem se situado de forma marginal, perdendo um imenso potencial para a geração de empregos, técnicas, tecnologias e produtos, devido, principalmente, à falta de incentivos para a formação de recursos humanos na área. Kits educacionais de robótica não possuem preços acessíveis, dificultando ainda mais a divulgação desse tema junto aos estudantes.

Por outro lado os dispositivos móveis estão cada vez mais presentes no cotidiano. Muitas pessoas possuem mais de um telefone celular, muitas vezes utilizando um para trabalho, outro para uso pessoal, ou diversas outras utilidades. Além disso, os preços são cada vez mais acessíveis, permitindo uma atualização do dispositivo mais rapidamente. Esses dispositivos apresentam componentes que podem ser utilizados em sistemas autônomos para execução de tarefas. Sensores como os de áudio e de vídeo são componentes importantes desses dispositivos e podem ser configurados para execução de tarefas feitas por um robô.

Este projeto consiste na utilização de dispositivos móveis para controlar um robô, tornando seu custo mais acessível e utilizando as diversas funcionalidades presentes em um celular para beneficiar o robô, tais como: câmera, conexão Wi-Fi, acelerômetro, GPS, Internet e microfone.

Em seguida, apresentaremos a base teórica do nosso trabalho, o Dual-Tone MultiFrequency (DTMF) e, posteriormente, explicaremos como o sistema foi construído.

\section{DTMF}

Sistemas de telefonia atuais utilizam DTMF para controle de equipamentos de comunicação e envio de dados de ligações telefônicas. DTMF é a sigla em inglês para "DualTone Multi-Frequency" (uma marca registrada da AT \& T) [1]. Tons são produzidos quando uma tecla do telefone é pressionada, correspondendo a um determinado digito. Para que o sistema fique mais robusto e imune a interferências e ruídos, utilizam-se duas frequências simultaneamente para representar um único digito, diminuindo assim as possíveis interferências externas.

Como o DTMF foi criado para ser robusto a interferências e trafegar em canais de áudio ruidosos, ele se adequa bem a nossa aplicação.

Quando um dígito é pressionado são emitidos dois tons de frequências específicas: uma alta e outra baixa. A relação dos números e suas respectivas frequências emitidas pode ser vista na tabela 1. 
Tabela 1 - Relação de botões e frequências emitidas

\begin{tabular}{|c|c|c|}
\hline Botão & Frequência Baixa $(\mathrm{Hz})$ & Frequência Alta $(\mathrm{Hz})$ \\
\hline 1 & 697 & 1209 \\
\hline 2 & 697 & 1477 \\
\hline 3 & 697 & 1209 \\
\hline 4 & 770 & 1336 \\
\hline 5 & 770 & 1477 \\
\hline 6 & 770 & 1209 \\
\hline 7 & 852 & 1336 \\
\hline 8 & 852 & 1477 \\
\hline 9 & 852 & 1209 \\
\hline 0 & 941 & 1336 \\
\hline$*$ & 941 & 1477 \\
\hline$\#$ & 941 & \\
\hline
\end{tabular}

\section{USO DE DTMF EM ROBÓTICA}

O uso da tecnologia DTMF em robôs não é novidade. Existem inúmeros projetos onde dígitos DTMF são enviados via linha telefônica para dar instruções a diversos tipos de robôs. Patil et al [2] implementaram um robô que recebe dígitos DTMF durante uma chamada telefônica, e interpreta estes dígitos para comandar seu robô. Manikandan et al [3] também desenvolveram um sistema robótico que é controlado a partir de teclas apertadas em um telefone celular remoto. Neste caso, o robô possui um telefone e o usuário outro, e o aperto das teclas no celular do usuário gera tons DTMF que são interpretados pelo robô. Sai e Sivaramakrishnan [4] também apresentaram recentemente um robô que utiliza um telefone celular e tons DTMF como controle remoto. Mais recentemente, Naskar et al [5] criaram um robô militar (com armas de fogo) para ser usado em campos de batalha. Neste sistema, o robô é controlado remotamente via rádio, mas a informação que é enviada pelo canal de rádio consiste em sequências de dígitos DTMF.

Em todos estes projetos, o foco não é operação autônoma do robô, mas sim o controle remoto destes. 


\section{IMPLEMENTAÇÃO}

Como discutido na seção anterior, os projetos passados e atuais que envolvem robótica e DTMF são focados em controle remoto, normalmente envolvendo um telefone celular no robô e um telefone em posse do usuário.

Contudo, existe uma outra possibilidade inovadora, que consiste em utilizar o próprio telefone celular como unidade de controle de um robô. $O$ telefone é instalando no próprio robô e tons DTMF são usados para o celular enviar comandos de movimentação para o robô.

O projeto utiliza os tons DTMF gerados no celular para fazer a movimentação do robô. Basicamente, a relação entre dispositivo móvel e robô acontece da seguinte maneira (Figura 1):

1) Quando uma tecla do celular é pressionada, esta gera um tom DTMF que é enviado para a sua saída de fone de ouvido;

2) O som é captado por meio de um cabo P2 diretamente ligado na entrada DTMF do circuito do robô, ou por um microfone amplificado;

3) Então, o DTMF é decodificado por meio de um Cl - MT8870 (DTMF Decoder) - que envia pulsos elétricos às quatro saídas que indicam a numeração em binário do número pressionado. Por exemplo, se foi pressionado o número 5 a saída é 0101.

4) Por fim, as saídas são conectadas a uma Ponte $H$ que fará a movimentação dos motores de acordo com os pulsos recebidos.

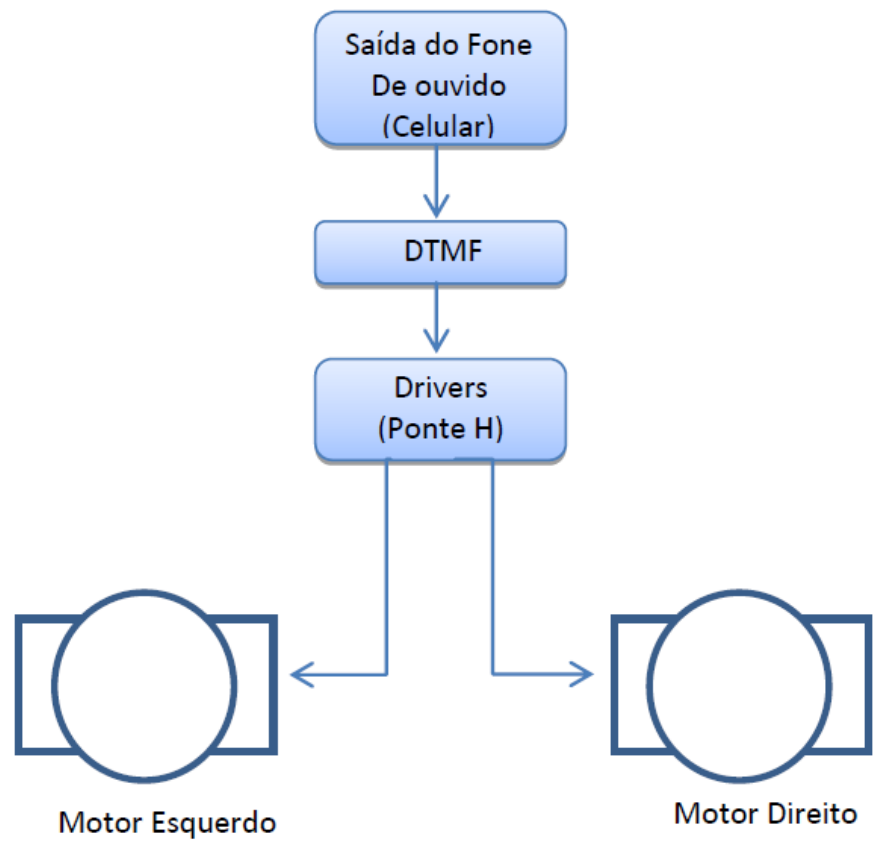

Figura 1 - Diagrama de Implementação. 
A tabela 2 mostra a movimentação do robô de acordo com o número pressionado.

Tabela 2 - Relação de botões e movimentação do robô

\begin{tabular}{|c|c|c|c|}
\hline Botão & Movimento & Binário Associado & Observação \\
\hline 0 & - & 0000 & $\begin{array}{c}\text { Mantêm os motores } \\
\text { parados }\end{array}$ \\
\hline 1 & Gira a Esquerda & 0001 & $\begin{array}{l}\text { Movimenta o motor } \\
\text { direito para frente }\end{array}$ \\
\hline 2 & Gira a Direita & 0010 & $\begin{array}{l}\text { Movimenta o motor } \\
\text { direito para trás }\end{array}$ \\
\hline 3 & - & 0011 & Movimento Inválido \\
\hline 4 & Gira a Direita & 0100 & $\begin{array}{l}\text { Movimenta o motor } \\
\text { esquerdo para frente }\end{array}$ \\
\hline 5 & Frente & 0101 & $\begin{array}{l}\text { Movimenta os dois } \\
\text { motores para frente }\end{array}$ \\
\hline 6 & Gira a Direita & 0110 & $\begin{array}{l}\text { Movimenta o motor } \\
\text { direito para trás e o } \\
\text { motor esquerdo para } \\
\text { frente }\end{array}$ \\
\hline 7 & - & 0111 & Movimento inválido \\
\hline 8 & Gira a Esquerda & 1000 & $\begin{array}{l}\text { Movimenta o motor } \\
\text { esquerdo para trás }\end{array}$ \\
\hline 9 & Gira a Esquerda & 1001 & $\begin{array}{l}\text { Movimenta o motor } \\
\text { direito para frente e } \\
\text { o esquerdo para trás }\end{array}$ \\
\hline$*$ & Ré & 1010 & $\begin{array}{l}\text { Movimenta os dois } \\
\text { motores para trás }\end{array}$ \\
\hline$\#$ & - & 1011 & Movimento inválido \\
\hline
\end{tabular}

Além disso, utilizamos também a modulação por largura de pulso, ou o PWM (Pulse Width Modulation) para controlar a velocidade de rotação do motor. O PWM corresponde à modulação do ciclo de trabalho (Duty cycle) de um sinal ou fontes de alimentação, mantendo a amplitude dos pulsos constantes e variando-se a largura de forma proporcional ao sinal modulador. Desta forma, é possível controlar o valor da alimentação entregue aos motores e consequentemente a sua velocidade de rotação.

Por fim, foi implementado um servidor web no celular que permite acessar remotamente o robô e enviar comandos de controle remoto. 


\section{RESULTADOS}

Para validar o protótipo, utilizamos um telefone celular com o sistema operacional Android. Utilizando o kit de desenvolvimento do Android [6], foi implementado um programa que recebe requisições via web e move os motores de acordo com o movimento desejado. A figura 2 mostra o programa em execução.

O programa utiliza a classe ToneGenerator disponível no SDK do Android, que permite facilmente gerar qualquer tom DTMF pelos alto falantes ou fone de ouvido do telefone celular. Assim é possível controlar a velocidade devido à utilização do PWM que é implementado em uma thread. Outro recurso interessante para robótica que foi implementado neste projeto é o sistema de reconhecimento de voz do Android, que funciona muito bem no reconhecimento de voz em português, possibilitando comandos do tipo "Ande 10 centímetros" ou "Vire à direita".

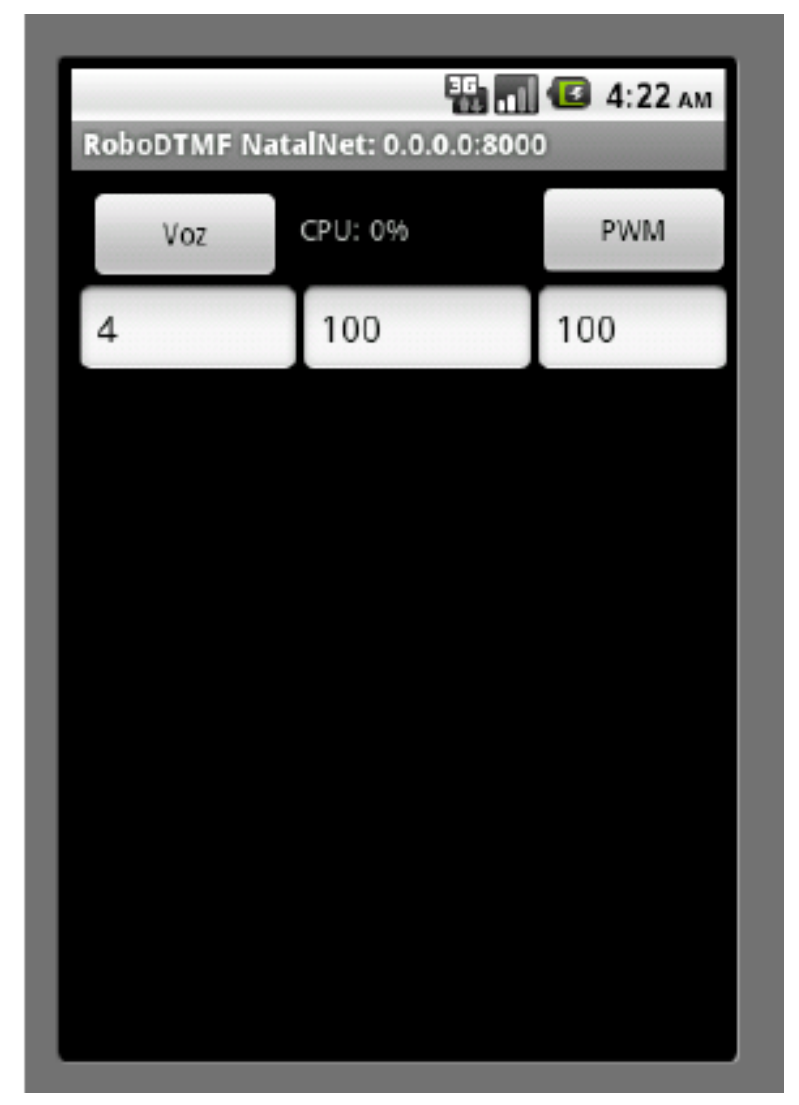

Figura 2 - Interface gráfica do programa para plataforma Android para geração de DTMF.

A movimentação do robô devido aos tons DTMF gerados pelo dispositivo móvel foi testada com êxito. Essa movimentação inclui todos os movimentos descritos na tabela 2, assim como a utilização do PWM para o controle da velocidade. A figura 3 apresenta o robô em funcionamento. 


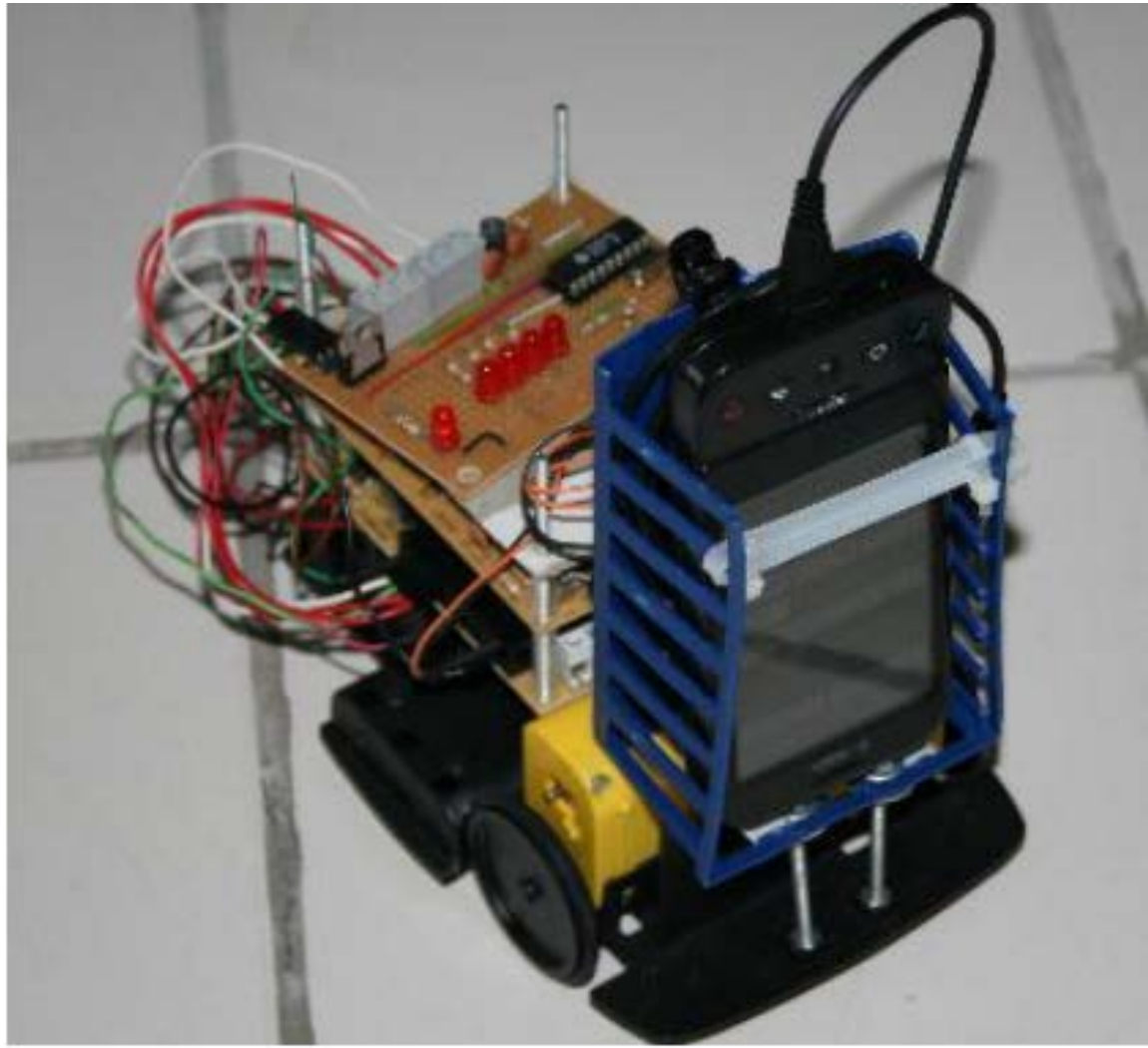

Figura 3 - Foto do protótipo do robô.

Finalmente, o custo total do robô foi de aproximadamente US\$30 (trinta dólares) que corresponde à estrutura de movimentação do robô (rodas, motores, painel) e o circuito interno (resistores, capacitores, DTMF Decoder e ponte H). Trata-se de um custo relativamente baixo e acessível para escolas e alunos brasileiros. Além disto, este preço pode ser reduzido com produção em maior escala.

\section{CONCLUSÃO}

Apresentamos neste artigo uma nova técnica para controlar robôs por meio de telefones celulares, utilizando apenas a saída de fones de ouvido do telefone. A utilização de um sistema robótico autônomo controlado por dispositivos móveis é uma solução para a difusão da robótica no Brasil e no mundo. Além disso, a opção de um kit de robótica de baixo custo também possibilita maior acessibilidade das classes mais baixas da sociedade, permitindo que, principalmente, crianças e adolescentes, possam desenvolver suas ideias criando seus próprios robôs. 


\section{AGRADECIMENTOS}

Os autores do trabalho expressam os agradecimentos ao CNPq pelo apoio financeiro.

\section{REFERÊNCIAS BIBLIOGRÁFICAS}

1. Yun Chan Choe; Joe Wook Jeon; "Remote robot control system based on DTMF of mobile phone", Industrial Informatics, 2008. INDIN 2008. 6th IEE International Conference.

2. Patil, B.C.; Henry, R.; , "Dual functional reconfigurable mobile robot," TENCON 2008 - 2008 IEEE Region 10 Conference, vol., no., pp.1-5, 19-21 Nov. 2008.

3. Manikandan, D.; Pareek, P.; Ramesh, P.; , "Cell phone operated robot," Emerging Trends in Robotics and Communication Technologies (INTERACT), 2010 International Conference on, vol., no., pp.183-184, 3-5 Dec. 2010.

4. Sai, K.V.S.; Sivaramakrishnan, R.; , "Design and fabrication of holonomic motion robot using DTMF control tones," Control, Automation, Communication and Energy Conservation, 2009. INCACEC 2009. 2009 International Conference on , vol., no., pp.1-4, 46 June 2009.

5. Naskar, S.; Das, S.; Seth, A.K.; Nath, A.; , "Application of Radio Frequency Controlled Intelligent Military Robot in Defense," Communication Systems and Network Technologies (CSNT), 2011 International Conference on , vol., no., pp.396-401, 3-5 June 2011.

6. Google Inc. Android SDK. On-Line. Disponível em: http://developer.android.com/sdk/index.html. Consulta em: 14/10/2011. 